\title{
Damage to dopaminergic neurons by oxidative stress in Parkinson's disease (Review)
}

\author{
JI-DONG GUO ${ }^{1 *}$, XIN ZHAO ${ }^{2 *}$, YANG LI $^{3}$, GUANG-REN LI $^{4}$ and XIAO-LIANG LIU ${ }^{5}$ \\ ${ }^{1}$ Department of Neurology, The First Affiliated Hospital of Beihua University, Jilin, Jilin 132011; ${ }^{2}$ Department of Paediatrics, \\ The First Hospital of Jilin University; ${ }^{3}$ Department of Neurology, The Third Hospital of Jilin University; \\ ${ }^{4}$ Department of Neurology, The Third Hospital of Jilin University; ${ }^{5}$ Cancer Center, The First Hospital of Jilin University, \\ Changchun, Jilin 130021, P.R. China
}

Received January 31, 2016; Accepted December 13, 2017

DOI: $10.3892 /$ ijmm.2018.3406

\begin{abstract}
Oxidative stress is increasingly recognized as a central event contributing to the degeneration of dopaminergic neurons in the pathogenesis of Parkinson's disease (PD). Although reactive oxygen species (ROS) production is implicated as a causative factor in PD, the cellular and molecular mechanisms linking oxidative stress with dopaminergic neuron death are complex and not well characterized. The primary insults cause the greatest production of ROS, which contributes to oxidative damage by attacking all macromolecules, including lipids, proteins and nucleic acids, leading to defects in their physiological function. Consequently, the defects in these macromolecules result in mitochondrial dysfunction and neuroinflammation, which subsequently enhance the production of ROS and ultimately neuronal damage. The interaction between these various mechanisms forms a positive feedback loop that drives the progressive loss of dopaminergic neurons in PD, and oxidative stress-mediated neuron damage appears to serve a central role in the neurodegenerative process. Thus,
\end{abstract}

Correspondence to: Professor Xiao-Liang Liu, Cancer Center, The First Hospital of Jilin University, 71 Xinmin Street, Changchun, Jilin 132021, P.R. China

E-mail: liuxiaoliangjiayi@163.com

*Contributed equally

Abbreviations: PD, Parkinson's disease; ROS, reactive oxygen species; $\mathrm{H}_{2} \mathrm{O}_{2}$, hydrogen peroxide; CNS, central nervous system; ETC, electron transport chain; OMM, outer mitochondrial membrane; IMM, inner mitochondrial membrane; VDAC, voltage dependent anion channel; ANT, adenine nucleotide translocator; mPTP, mitochondrial permeability transition pore; HNE, 4-hydroxyl-2-nonenal; Apaf1, apoptotic protease activating factor 1 ; $\mathrm{SN}$, substantia nigra; mtDNA, mitochondrial DNA; $\mathrm{MPP}^{+}$, 1-methyl-4-phenylpyridinium; MPTP, 1-methyl-4-phenyl-1,2,3,6-tetrahydropyridine

Key words: Parkinson's disease, reactive oxygen species, oxidative stress, apoptosis understanding the cellular and molecular mechanisms by which oxidative stress contributes to the loss of dopaminergic neurons may provide a promising therapeutic approach in PD treatment.

\section{Contents}

1. Introduction

2. Mitochondrial complex inhibition and ROS production

3. Vulnerability of dopaminergic neurons to oxidative stress

4. Reactive oxygen species and mitochondrial dysfunction

5. Oxidative stress and the opening of the mPTP

6. Oxidative stress and neuroinflammation

7. Damage to nucleic acids by oxidative stress

8. Conclusion

\section{Introduction}

Parkinson's disease (PD) is the most common movement disorder and is clinically characterized by motor symptoms, including bradykinesia, resting tremors, rigidity and postural instability, caused by the progressive degeneration of dopaminergic neurons in the sustantia nigra (SN) (1). While the underlying mechanisms contributing to the damage of dopaminergic neuron remains poorly understood, oxidative stress has been considered to be strongly linked to the loss of neurons in PD $(2,3)$. Studies in postmortem brains have shown the increased levels of 4-hydroxyl-2-nonenal (HNE), a by-product of lipid peroxidation, carbonyl modifications of soluble proteins, and the DNA and RNA oxidation products 8-hydroxy-deoxyguanosine and 8-hydroxy-guanosine in the SN of PD patients (4-8). The link between oxidative stress and the pathogenesis of PD is further supported by animal models induced by neurotoxins, including 1-methyl-4-phenyl-1,2,3,6-tetrahydropyridine (MPTP), rotenone and 6-hydroxydopamine (6-OHDA), which cause the production of ROS and the progressive loss of dopaminergic neurons (9-11). Oxidative stress is an imbalance in the rate of reactive oxygen species (ROS) production and the rate of ROS scavenging, resulting in excessive accumulation of 
ROS (12). These ROS attack all macromolecules, including lipids, proteins and nucleic acids, and trigger an inflammatory response, resulting in cellular damage, mitochondrial dysfunction, oxidative DNA injury and neuroinflammation, all of which have been considered as key contributors in the neurodegenerative process of PD (13-16). Oxidative stress appears to be a central event associated with the development of PD by activating the cascade of events leading to the degeneration of these dopaminergic neurons. The present review stresses the fundamental pathological pathway of oxidative stress in the development of PD, in order to gain a better understanding of the underlying mechanisms, and to provide available evidence and future directions for potential effective therapeutic targets with enhanced efficacy in the prevention and treatment of PD.

\section{Mitochondrial complex inhibition and ROS production}

Mitochondria are important organelles for the maintenance of cellular homeostasis by generating and supplying energy for the cells through oxidative phosphorylation. The process of oxidative phosphorylation involves the interaction of unpaired electrons with molecular $\mathrm{O}_{2}$, resulting in the generation of a superoxide radical, an amphibolic radical that cannot easily pass through biological membranes $(17,18)$. Subsequently, the radical $\mathrm{O}_{2}^{-}$is converted by the mitochondrial superoxide dismutase or manganese superoxide dismutase to form hydrogen peroxide $\left(\mathrm{H}_{2} \mathrm{O}_{2}\right)$ in the mitochondria (19). $\mathrm{H}_{2} \mathrm{O}_{2}$ is a relatively inactive compound that is released from the mitochondria into the cellular cytosol and nucleus where it contributes to oxidative stress. In the presence of reduced ferrous iron, $\mathrm{H}_{2} \mathrm{O}_{2}$ can be converted into the highly reactive hydroxyl radical, leading to further oxidative damage (20). It is widely accepted that complex I inhibition and a subsequent increase in the production of ROS is a leading cause responsible for the loss of dopaminergic neurons in PD $(3,14,21)$. The first evidence for the link between complex I inhibition with subsequent oxidative stress and the pathogenesis of PD was the recognition that complex I inhibitor MPTP can cause acute and irreversible parkinsonian symptoms in humans (22). Subsequently, the molecular mechanism underling the neurotoxicity of MPTP was also intensively studied. MPTP is a lipophilic molecule that can rapidly cross the blood-brain barrier. In the brain it is oxidized to form the toxic metabolite 1-methyl-4-phenylpyridinium $\left(\mathrm{MPP}^{+}\right)$by type B monoamine oxidase (23). $\mathrm{MPP}^{+}$is a substrate for the dopamine transporter and can be taken up selectively into dopaminergic neurons, accumulating in the mitochondria, where it inhibits respiration complex I of the mitochondrial electron transport chain (ETC), leading to the production of ROS (24). Postmortem studies in patients with idiopathic PD have shown the disease-specific deficits in mitochondrial complex I activity in the SN $(25,26)$. This change is not limited to the SN of the brain, and mitochondrial dysfunction and complex I inhibition have also been reported in peripheral tissues, including the striatum, cortical brain tissue, blood platelets, fibroblasts, skeletal muscle and lymphocytes, in PD (27-33). Administration of rotenone, a well-known complex I inhibitor, was previously shown to cause selective nigral dopaminergic neuron loss and a significant reduction in complex I activity, and this toxicity was significantly attenuated by methylene blue, which functioned as an alternative electron carrier to bypass complex I blockage, further supporting the involvement of mitochondrial complex inhibition in PD pathogenesis (34). Although the downstream events of mitochondrial dysfunction that cause neuronal cell death are not completely understood, oxidative stress caused by ROS production is strongly suggested to be involved in the neurodegenerative process $(3,14,21)$. Mitochondria are the primary intracellular source of ROS, and respiratory chain complexes, especially complex I, are sites of ROS production (35-37). This production of ROS in turn damages the components of the respiratory chain, particularly complex I, leading to its further inhibition and greater ROS production. Normally, the toxicity of ROS can be detoxified by diverse defence mechanisms; for instance, as the primary ROS superoxide radicals can be catalyzed into $\mathrm{O}_{2}$ and $\mathrm{H}_{2} \mathrm{O}_{2}$ by the superoxide dismutase, which is expressed in nearly all living organisms (14), $\mathrm{H}_{2} \mathrm{O}_{2}$ can be catalized by glutathione peroxidase and catalase into $\mathrm{H}_{2} \mathrm{O}$ and $\mathrm{O}_{2}$. Oxidative damage occurs when the balance between the production of ROS and antioxidant defence is perturbed, and excessive ROS accumulate (38). Excessive ROS can damage all macromolecules, including lipids, proteins and nucleic acids, leading to defects in their physiological functions. The central nervous system (CNS), particularly dopaminergic neurons, is more prone to oxidative damage, resulting in the degeneration of the cell and PD pathogenesis (39).

\section{Vulnerability of dopaminergic neurons to oxidative stress}

The CNS contains a large number of mitochondria in order to meet the demands of high levels of energy consumption. Therefore, the iron content in CNS cells is particularly high, since numerous mitochondrial enzymes require iron to function, leading to the greater generation of ROS that contribute to oxidative stress and subsequently the degeneration of neurons (40). Iron promotes the generation of highly reactive oxygen species, resulting in further oxidative damage, particularly for nigral dopaminergic neurons that appear to exhibit increased sensitivity to iron-induced oxidative stress. Studies in postmortem brains of PD patients have shown higher levels of iron in the SN compared with that in controls $(41,42)$. The link of oxidative iron dysregulation with the neurodegenerative process is also supported by PD animal models, where increased levels of iron and hyroxyl radicals could be detected in the SN (43). Administration of desferrioxamine, an iron chelator, significantly decreases the levels of iron in the brain and protects against neurodegeneration induced by iron and MPTP in PD mouse models (44), further supporting the contribution of iron in the neurodegenerative process of PD. Furthermore, the brain is enriched in lipids that participate in membrane fluidity and permeability, and mediate the inflammatory processes and apoptotic signals (45). The lipids are susceptible to ROS-mediated damage, particularly polyunsaturated fatty acids, which are the most prone to lipid peroxidation, resulting in the structural damage of membranes, consequent neuronal damage and ultimately, mortality (14). Oxidative stress-mediated death mechanism has been underlied in the pathogenesis of PD (39). Higher levels of malondialdehyde, a production of polyunsaturated fatty acid peroxidation in oxidative conditions, have also been reported in $\mathrm{SN}$ compared with that in other brain regions in PD (46). The lipid peroxidation marker, cholesterol lipid hydroperoxide, is also detected as significantly increased 


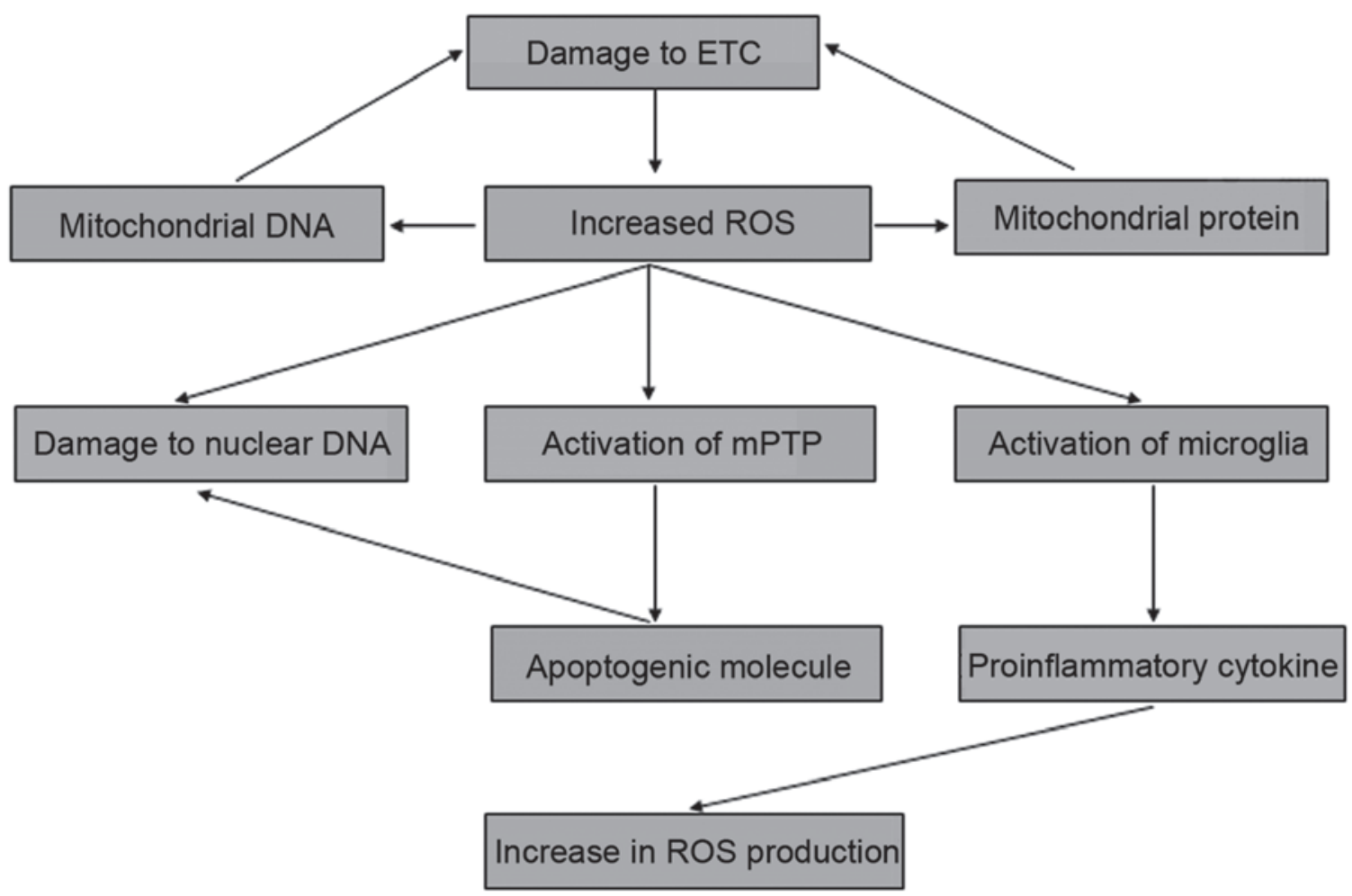

Figure 1. ROS trigger a cascade of events leading to the degeneration of neurons. Oxidative stress serves a central role in the neurodegenerative process by triggering the cascade events, including mitochondrial dysfunction, impairment of nuclear and mitochondrial DNA, and neuroinflammation, which in turn cause more ROS production, thus forming a vicious cycle. These vicious cycles generate an uncontrolled pathogenesis conndition that drives the progressive degeneration of dopaminergic neurons in Parkinson's disease. ROS, reactive oxygen species; ETC, electron transport chain; mPTP, mitochondrial permeability transition pore.

in PD brains compared with that in control subjects (47). The reinforcement of peroxidation of polyunsaturated fatty acids to oxidative damage of dopaminergic neurons is also supported by the elevated levels of HNE detected in the SN and the cerebrospinal fluid of PD patients $(5,48)$. HNE is a lipid peroxidation product contributing to apoptotic cell death via the activation of the caspase cascade and the subsequent induction of DNA fragmentation (49). HNE can also reduce the levels of glutathione (GSH) resulting in the vulnerability of the neurons to oxidative attack, since GSH is a major non-enzymatic antioxidant in the CNS (50). Additionally, other causal factors that are associated with the vulnerabilities of dopaminergic neurons to oxidative stress have been well documented (39). Taken together, these results indicate that the dopaminergic neurons are more vulnerable to oxidative attack. Although the mechanisms of oxidative damage in response to oxidative stress causing the progressive degeneration of dopaminergic neurons in PD is unclear, events such as mitochondrial dysfunction, the opening of the mitochondrial permeability transition pore (mPTP), neuroinflammation and oxidative DNA damage induced by oxidative stress may serve crucial roles in the process of neurodegeneration. The interaction between these various mechanisms forms a positive feedback loop that drives uncontrolled pathogenesis conditions, resulting in the development of PD (Fig. 1).

\section{Reactive oxygen species and mitochondrial dysfunction}

Mitochondria are the primary intracellular source of ROS, and for this reason the organelles are frequently exposed to oxidative stress $(51,52)$. The complex of the ETC is one of the main cellular targets of ROS-induced oxidative stress, and oxidative damage of the ETC leads to the inhibition of ATP production and further generation of ROS (53). Consequently, the vicious cycle between the defects in the ETC and the subsequent production of ROS drive the uncontrolled oxidative stress that may play a central role in the progressive degeneration of dopaminergic neurons and have been underlied in PD pathogenesis (3). The proteins of the ETC complex are encoded by mitochondrial and nuclear genomes. Mitochondrial DNA (mtDNA) encodes 13 proteins that are all ETC complex subunits involved in oxidative phosphorylation and ATP production (54). Due to the proximity to the ETC complexes and the lack of histone protein protection, mtDNA is vulnerable to ROS attack (55). The damage to mtDNA and subsequent defects in the production of these proteins could induce mitochondrial dysfunctions that are implicated in a multitude of diseases or pathological conditions (53). The accumulation of defects in mtDNA has been detected in nigral dopaminergic neurons of elderly individuals and sporadic PD subjects (56-58). Inhibition of mtDNA expression leads to dysfunction in the respiratory chain in dopaminergic neurons accompanied by progressive parkinsonism in mouse models (59). High levels of mtDNA deletions could be also detected in the midbrain brains of PD models induced by rotenone, which inhibits ETC, resulting in the production of ROS (60). These studies suggest that oxidative ETC and mtDNA damage may be involved in the degeneration of dopaminergic neurons in oxidative conditions. 
Mitochondria are crucial organelles for $\mathrm{Ca}^{2+}$ storage, and mitochondrial $\mathrm{Ca}^{2+}$ is important in the regulation of diverse cellular functions (61). The synthesis of ATP, for example, is dependent on $\mathrm{Ca}^{2+}$ signals to promote the flow of electrons down the respiratory chain by increasing the mitochondrial NADH-to-NAD ratio through the activation of the dehydrogenases in the mitochondria $(62,63)$. The maintenance of a $\mathrm{Ca}^{2+}$ gradient between the cytosol and the mitochondrial matrix is important for mitochondrial functions. The driving force of mitochondrial $\mathrm{Ca}^{2+}$ uptake is mainly dependent on the mitochondrial transmembrane potential across the inner mitochondrial membrane (IMM), which translocates $\mathrm{H}^{+}$ions to the intermembrane space (IMS) and generates a membrane potential difference (64). Mitochondrial $\mathrm{Ca}^{2+}$-mediated nitric oxide synthase activation may result in increased production of $\mathrm{NO}^{\circ}$. The interaction of $\mathrm{NO}^{-}$with $\mathrm{O}_{2}{ }^{-}$produces a highly reactive radical $\mathrm{ONOO}^{-}$that causes further damage to ETC and more ROS production $(53,65,66)$. In fact, an increase in mitochondrial $\mathrm{Ca}^{2+}$ has been reported to increase production of ROS in neurons, resulting in oxidative ETC damage (67). This has particularly importance in dopaminergic neurons with exposure to frequent influxes of calcium (68). The interaction between $\mathrm{Ca}^{2+}$ overload and ROS production causes further damage to the ETC and uncontrolled oxidative stress, resulting in mitochondrial lipid, protein and DNA oxidation, and subsequetly, cytotoxicity (69). The vicious circle between $\mathrm{Ca}^{2+}$ overload and oxidative stress favors the sustained opening of the PTP, which causes the mitochondrial membrane potential to collapse and the mitochondria to swell, resulting in pro-apoptotic mediator release into the cytosol from the mitochondria (70-72). The opening of the $\mathrm{MPTP}$ has been reported to serve a crucial role in the pathogenesis of neurodegenerative disorders, including PD $(73,74)$.

\section{Oxidative stress and the opening of the mPTP}

The MPTP is a poly-protein transmembrane channel that is formed at contact sites between the outer mitochondrial membrane (OMM) and the IMM. Despite controvery over the structural constituents of the mPTP, the voltage-dependent anion channel (VDAC) in the OMM, the adenine nucleotide translocator (ANT) in the IMM, the B-cell lymphoma-2 (Bcl-2) family proteins in the cytosol and cyclophilin D (CyPD) in the matrix appear to be essential components (53). Normally, mPTP is impermeable, and the VDAC and the ANT are separated by the IMS. The opening of the MPTP occurs during the interaction of the ANT with the VDAC, and CyPD serves a crucial role in this process (75). Generally, CyPD is a mitochondrial matrix protein. When activated under the condition of oxidative stress, this protein can be translocated to the IMM where it interacts with the ANT and changes its conformation, leading to the binding of the ANT to the VDAC and the subsequent activation of the MPTP (75). The permeation of the OMM depends on the Bcl-2 family of proteins, including Bcl-2-associated $\mathrm{X}$ protein (Bax) and Bcl-2 homologous killer (Bak) (76). These proteins are located in the cytosol, but translocate and oligomerize into the OMM in response to oxidative stress. ROS promote the translocation of CyPD to the IMM, and Bax and Bak to the OMM, thus serving a crucial role in the opening of the MPTP (53). The opening causes the collapse of the mitochondrial transmembrane potential and the disturbance of the $\mathrm{H}^{+}$gradient across the IMM, which inhibits the production of ATP and causes further generation of ROS, ultimately leading to cell death $(77,78)$. The release of mitochondrial apoptogenic proteins from the opening pore into the cytosol serves a crucial role in mPTP-mediated cell death, of which cytochrome $c$ is the most potent apoptotic inducer $(79,80)$. The released cytochrome $c$ triggers the activation of caspase- 9 via the interaction with apoptotic protease-activating factor 1 (Apaf1) (80). Apaf1 is a cytoplasmic protein that contains several domains associated with its functional and regulatory role (81). The binding of cytochrome $c$ with the special domain of Apaf1 results in the protein forming an oligomeric apoptosome that is required for the activation of pro-caspase-9. Caspase- 9 cleaves pro-caspase- 3 resulting in its activation and the subsequent cleavage of DNA, the irreversible step toward apoptotic cell death (79,80). Apoptosis-inducing factor (AIF) is another apoptotic factor released from the mitochondria into the cytosol triggering caspase-independent apoptosis (53). AIF is a mitochondrial protein expressed in the IMS between the IMM and the OMM, and can be released in response to apoptotic signaling (82). The cytosolic AIF then translocates to the nucleus where it binds to DNA to instigate chromatin condensation (83) (Fig. 2). The contribution of other apoptotic mediators released from the opening of the MPTP to apoptosis has been well documented $(53,84)$. Several mechanisms have been revealed to antagonize the opening of the $\mathrm{mPTP}$. The translocation and oligomerization of Bax and Bak into the OMM, for example, can be antagonized by the antiapoptotic proteins $\mathrm{Bcl}-2$ and $\mathrm{Bcl}-\mathrm{xL}$ via sequestration and inhibition of the activator proteins that are required for the activation of these pro-apoptosis proteins (84). Glycogen synthase kinase-3 $\beta$ (GSK-3 $\beta$ ) can be also implicated in the modulation of the opening of mPTP $(85,86)$. GSK-3 $\beta$ is a Ser/Thr protein kinase expressed in the cytosol, nucleus and mitochondria of all eukaryotic cells, and is involved in modulating a wide range of biological functions $(87,88)$. GSK-3 $\beta$ activation promotes the upregulation of the levels of Bax $(89,90)$, and facilitates its mitochondrial localization by directly phosphorylating Ser163 of this protein (91). Mitochondrial GSK-3 $\beta$ modulates the process of oxidative phosphorylation that is implicated in the production of ROS, the key inducer of the opening of the mPTP (92). Studies in cell and animal models of PD have shown that GSK-3 $\beta$ inhibition can protect dopaminergic neurons from the toxicity of $\mathrm{MPP}^{+} / \mathrm{MPTP}$ (93-96), and the blockage of the opening of the MPTP may be involved (97). Overall, the oxidative stress-mediated opening of the MPTP is one of the pathways responsible for the apoptosis of dopaminergic neurons in PD, and understanding the mechanisms involved is essential to the development of effective therapies for neurodegenerative diseases.

\section{Oxidative stress and neuroinflammation}

Neuroinflammation is a protective mechanism of the CNS against infectious insults and injury by activation of the innate immune system in the brain to destroy and remove the detrimental agents and injured tissues (98). However, uncontrolled inflammation can cause excessive cell and tissue 


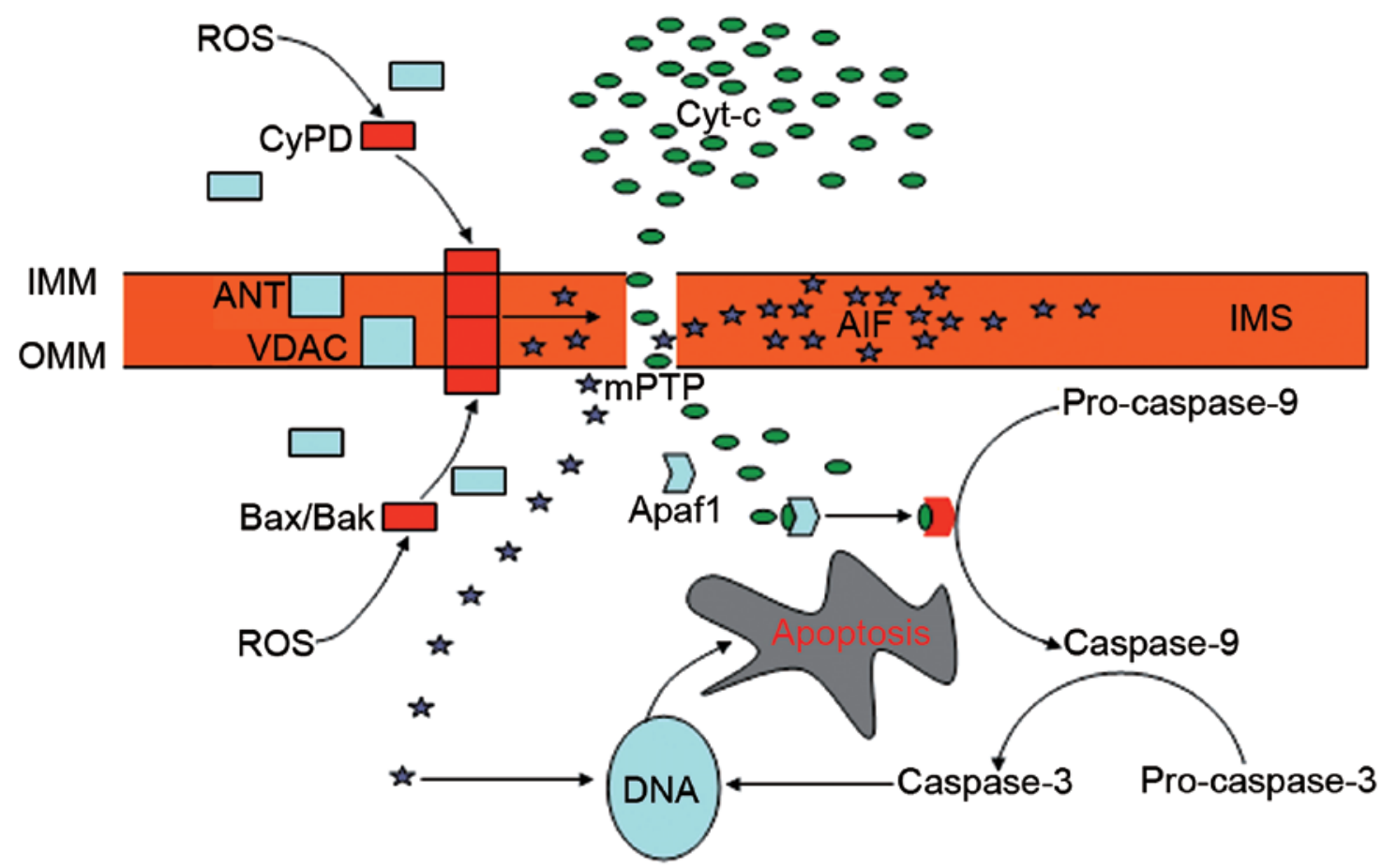

Figure 2. ROS facilitate the opening of the mPTP, resulting in neuronal apoptosis. The mPTP is a poly-protein transmembrane channel structurally consisted of a number of constituents, including the VDAC in the OMM, the ANT in the IMM, the Bcl-2 family of proteins in the cytosol and CyPD in the matrix. ROS are a crucial inducer in the opening of the MPTP. Under oxidative conditions, the cytosol proteins Bax and Bak translocate and oligomerize into the OMM resulting in the permeation of the OMM. ROS can also activate the mitochondrial matrix protein CyPD, thus facilitating its translocation to the IMM. The translocated CyPD interacts with ANT and changes its conformation, leading to the binding of ANT to VDAC and subsequently, mPTP activation. The opening of the mPTP releases pro-apoptotic mediators, including cytochrome $c$, from the mitochondria into the cytosol. The released cytochrome $c$ triggers the activation of pro-caspase-9 via the interaction with Apaf1. Caspase-9 cleaves pro-caspase-3 resulting in its activation and subsequent DNA cleavage. AIF is another apoptotic factor released from the IMS between the IMM and the OMM through the MPTP into the cytosol. The cytosolic AIF is then translocated to the nucleus where it binds to DNA to instigate chromatin condensation. ROS, reactive oxygen species; mPTP, mitochondrial permeability transition pore; VDAC, voltage-dependent anion channel; OMM, outer mitochondrial membrane; ANT, adenine nucleotide translocator; IMM, inner mitochondrial membrane; Bcl-2, B-cell lymphoma-2; CyPD, cyclophilin D; Bax, Bcl-2-associated X protein; Bak, Bcl-2 homologous killer; Apaf1, apoptotic protease-activating factor 1; AIF, apoptosis inducing factor; IMS, intermembrane space.

damage, ultimately leading to chronic inflammation and progressive destruction of normal tissue. The elevated levels of ROS production serve an important role in the activation of a strong proinflammatory response, and the link between oxidative stress and inflammation and tissue injury has been well documented (15). The inflammatory damage has been underlied in the pathogenesis of neurodegenerative diseases, including Alzheimer's disease, Huntington's disease, multiple sclerosis and PD (99-102). The inflammatory response is a complex process involved in a series of cellular and molecular processes, including the activation of immune cells, the induction of certain intracellular signaling pathways and the release of inflammatory mediators in the brain (103). The activation of microglia is an initiator in inflammation-mediated neuronal injury. Microglia are the resident immune cells of the brain that become activated in response to brain injury or immune challenge (104). Activated microgli are an important source of superoxide and nitric oxide, triggers of oxidative and nitrative stress in neurotoxicity; they can also produce proinflammatory cytokines such as glutamate and tumor necrosis factor- $\alpha$ (TNF- $\alpha$ ), which are potentially toxic agents in the brain microenvironment (104-106). Inflammation-derived oxidative stress and cytokine-dependent toxicity have been suggested to be involved in the loss of dopaminergic neurons in PD (107-109). Postmortem studies revealed the presence of inducible NO synthase (iNOS) and proinflammatory cytokines, including TNF- $\alpha$, interleukin- $1 \beta$ (IL-1 $\beta$ ), IL-2 and IL- 6 , in the SN of PD patients (110-112). A series of proinflammatory cytokines, including TNF- $\alpha$, IL- $1 \alpha, \mathrm{IL}-1 \beta$ and IL- 6 , and activated microglia have also been identified in PD animal models (113-118). As one important cytokine, TNF serves a crucial role in inflammation-mediated neurodegeneration, since elavated levels of this cytokine can be persistently detected in the affected areas of the SN in PD (119). In addition to the induction of proinflammatory signaling pathways resulting in cell damage (16), TNF can promote the secretion of $\mathrm{NO}$ by increasing the expression of iNOS in microglia (120). Furthermore, TNF can activate NADPH oxidases, leading to the production of ROS, which contribute to oxidative stress and in turn result in an uncontrolled inflammatory response (16). The dopaminergic neurons are particularly susceptible to microglia-mediated toxicity due to the highest density of microglial cells being distributed in the $\mathrm{SN}$ of the brain $(121,122)$. Microglia activation promotes the production of proinflammatory cytokines, which cause dopaminergic nigrostriatal neuron degeneration in MPTP models of PD (123). Animal models of PD have shown that suppression of the inflammatory response, results in the protection of neurons from the damage induced by neurotoxin $(124,125)$. These data indicate a close association between microglial activation and the degeneration of dopaminergic neurons in PD pathogenesis. 
Dopaminergic neuronal death releases noxious endogenous mediators, including oxidized proteins, lipids and DNA, in the extracellular space, which can also activate the microglia, resulting in the release of multiple proinflammatory cytokines. Proinflammatory factor prodcution subsequently exacerbates damage to the neurons via oxidative stress and cytokine toxicity (19), causing the injured neurons to release further noxious endogenous mediators and resulting in a continuous inflammatory response (104). This positive feedback loop between activated microglia and damaged neurons forms a neurotoxic vicious cycle and an uncontrolled, prolonged inflammatory process, and is hypothesized to be partially responsible for the gradual loss of dopaminergic neurons in PD $(126,127)$. Thereby, inhibiting the inflammatory response generated by microglia activation may be show benefits in neurodegenerative conditions.

\section{Damage to nucleic acids by oxidative stress}

DNA integrity is required for cell survival. Under physiopathologycial conditions, DNA is often subjected to damage by endogenous and environmental toxic agents, and unrepaired DNA damage leads to genetic and protein instability, and subsequent cell death. Nucleic acids, RNA and DNA, are particularly susceptible to oxidative damage, with DNA damage being a key contributor to a number of different diseases (128). Dopaminergic neurons are frequently exposed to ROS attack, resulting in DNA oxidative damage due to the high levels of ROS production. In PD, increased levels of 8-hydroxyguanine, the marker of DNA oxidative damage, have been detected selectively in the SN $(7,129)$. The number of strand breaks in nuclear DNA have also been reported to be elevated in the SN compared with that in other areas of the brain, and evidence of alterations to DNA conformation and stability in the SN has also been documented (129). mDNA is more susceptible to oxidative damage than nuclear DNA (130). Postmortem studies in the brains of patients with PD have shown increased levels of mtDNA damage marker abasic sites in the SN. Abasic sites were also shown in brain tissue from PD mouse models treated with the neuronal toxin rotenone, which causes oxidative stress by inhibiting the mitochondrial complex (131). Abasic sites are DNA segments that have lost a purine or pyrimidine base, leading to the blockage of the polymerase during the replication and transcription of DNA (132). These studies demonstrate that dopaminergic neuron injury could be ascribed to the oxidative damage of nuclear DNA and mtDNA, which alters its coding properties or interferes with normal metabolic function, and subsequently results in cell death (128). ROS attack on DNA may be reversible or irreversible, dependent on the efficiency of its repair. Effective repair of damaged DNA is required to preserve its integrity and maintain the viability of the cell, particularly in dopaminergic neurons. A number of cellular mechanisms are devoted to the repair of DNA (133). A previous study determined an association between variants in DNA repair and an increased risk of PD (134). As a critical regulatory protein for DNA repair, proliferating cell nuclear antigen (PCNA) serves a central role in the repair of damaged DNA in a variety of pathological conditions via the interaction with numerous enzymes and regulatory proteins $(135,136)$. PCNA-dependent repair of
DNA has been reported to contribute to the reserve in the DNA integrity of the dopaminergic neurons under oxidative conditions $(137,138)$. We previously studied in vitro the mechanism of the degeneration of dopaminergic neurons in PC12 cells induced by $\mathrm{MPP}^{+}$, which causes ROS production by inhibiting complex I, leading to oxidative DNA damage and subsequent neuronal cell death. The results showed that $\mathrm{MPP}^{+}$treatment significantly reduced PCNA expression in the neuronal PC12 cells and increased the level of cell apoptosis. The reversal of PCNA expression markedly promoted cell survival in PC12 cells with $\mathrm{MPP}^{+}$-induced neurotoxicity, supporting the hypothesis of the PCNA-dependent apoptotic pathway as a potential molecular mechanism in PD pathogenesis associated with DNA damage in oxidative conditions (139). These results may provide a potential target for the reversal of oxidative DNA damage-mediated neuronal death in PD pathogenesis.

\section{Conclusion}

The pathogenesis and progression of PD are complex and involved in a series of diverse mechanisms that alone or together contribute to the damage and gradual loss of dopaminergic neurons. Oxidative stress appears to serve a central role in the neurodegenerative process, since dopaminergic neurons are frequently exposed to oxidative stress, which triggers a cascade of events, including mitochondrial dysfunction, impairment of nuclear DNA and mtDDA, and neuroinflammation, which in turn cause more ROS production. The formation of this vicious cycle may serve a central role in the progressive degeneration of dopaminergic neurons in PD, therefore, the inhibition of the production of ROS and the blockage of the interactions in the signaling pathway may alleviate the severity and development of the disease. This require further elucidation.

\section{Acknowledgements}

This study was supported by Technology Research of the Education Department of Jilin Province, China (grant no. JJKH20170047K) to Ji-Dong Guo and the Department of Health of Jilin Province, China (grant no. 2016J078) to Ji-Dong Guo.

\section{Competing interests}

The authors declare that they have no competing interests.

\section{References}

1. Sulzer D and Surmeier DJ: Neuronal vulnerability, pathogenesis, and Parkinson's disease. Mov Disord 28: 715-724, 2013.

2. Shukla V, Mishra SK and Pant HC: Oxidative stress in neurodegeneration. Adv Pharmacol Sci 2011: 572634, 2011.

3. Kim GH, Kim JE, Rhie SJ and Yoon S: The role of oxidative stress in neurodegenerative diseases. Exp Neurobiol 24: 325-340, 2015

4. Jenner P: Oxidative stress in Parkinson's disease. Ann Neurol 53 (Suppl 3): S26-S38, 2003.

5. Yoritaka A, Hattori N, Uchida K, Tanaka M, Stadtman ER and Mizuno Y: Immunohistochemical detection of 4-hydroxynonenal protein adducts in Parkinson disease. Proc Natl Acad Sci USA 93: 2696-2701, 1996

6. Floor E and Wetzel MG: Increased protein oxidation in human substantia nigra pars compacta in comparison with basal ganglia and prefrontal cortex measured with an improved dinitrophenylhydrazine assay. J Neurochem 70: 268-275, 1998. 
7. Alam ZI, Jenner A, Daniel SE, Lees AJ, Cairns N, Marsden CD, Jenner P and Halliwell B: Oxidative DNA damage in the parkinsonian brain: An apparent selective increase in 8-hydroxyguanine levels in substantia nigra. J Neurochem 69: 1196-1203, 1997.

8. Isobe $\mathrm{C}, \mathrm{Abe} \mathrm{T}$ and Terayama Y: Levels of reduced and oxidized coenzyme Q-10 and 8-hydroxy-2'-deoxyguanosine in the cerebrospinal fluid of patients with living Parkinson's disease demonstrate that mitochondrial oxidative damage and/or oxidative DNA damage contributes to the neurodegenerative process. Neurosci Lett 469: 159-163, 2010.

9. Callio J, Oury TD and Chu CT: Manganese superoxide dismutase protects against 6-hydroxydopamine injury in mouse brains. J Biol Chem 280: 18536-18542, 2005.

10. Perier C, Bové J, Vila M and Przedborski S: The rotenone model of Parkinson's disease. Trends Neurosci 26: 345-346, 2003.

11. Burns RS, Chiueh CC, Markey SP, Ebert MH, Jacobowitz DM and Kopin IJ: A primate model of parkinsonism: Selective destruction of dopaminergic neurons in the pars compacta of the substantia nigra by N-methyl-4-phenyl-1,2,3,6-tetrahydropyridine. Proc Natl Acad Sci USA 80: 4546-4550, 1983.

12. Bhandary B, Marahatta A, Kim HR and Chae HJ: An involvement of oxidative stress in endoplasmic reticulum stress and its associated diseases. Int J Mol Sci 14: 434-456, 2012.

13. Federico A, Cardaioli E, Da Pozzo P, Formichi P, Gallus GN and Radi E: Mitochondria, oxidative stress and neurodegeneration. J Neurol Sci 322: 254-262, 2012.

14. Sanders LH and Greenamyre JT: Oxidative damage to macromolecules in human Parkinson disease and the rotenone model Free Radic Biol Med 62: 111-120, 2013.

15. Peterson LJ and Flood PM: Oxidative stress and microglial cells in Parkinson's disease. Mediators Inflamm 2012: 401264, 2012.

16. Fischer R and Maier O: Interrelation of oxidative stress and inflammation in neurodegenerative disease: Role of TNF. Oxid Med Cell Longev 2015: 610813, 2015.

17. Andreyev AY, Kushnareva YE and Starkov AA: Mitochondrial metabolism of reactive oxygen species. Biochemistry (Mosc) 70 200-214, 2005

18. Cadenas E and Davies KJ: Mitochondrial free radical generation, oxidative stress, and aging. Free Radic Biol Med 29: 222-230, 2000.

19. Rush JD and Koppenol WH: Oxidizing intermediates in the reaction of ferrous EDTA with hydrogen peroxide. Reactions with organic molecules and ferrocytochrome c. J Biol Chem 261: 6730-6733, 1986.

20. Gutteridge JM: Superoxide-dependent formation of hydroxyl radicals from ferric-complexes and hydrogen peroxide: An evaluation of fourteen iron chelators. Free Radic Res Commun 9: $119-125,1990$.

21. Subramaniam SR and Chesselet MF: Mitochondrial dysfunction and oxidative stress in Parkinson's disease. Prog Neurobiol 106-107: 17-32, 2013.

22. Langston JW, Ballard P, Tetrud JW and Irwin I: Chronic Parkinsonism in humans due to a product of meperidine-analog synthesis. Science 219: 979-980, 1983

23. Chiba K, Trevor A and Castagnoli N Jr: Metabolism of the neurotoxic tertiary amine, MPTP, by brain monoamine oxidase. Biochem Biophys Res Commun 120: 574-578, 1984.

24. Javitch JA, D'Amato RJ, Strittmatter SM and Snyder SH: Parkinsonism-inducing neurotoxin, N-methyl-4-phenyl-1,2,3,6 -tetrahydropyridine: Uptake of the metabolite $\mathrm{N}$-methyl-4-phenylpyridine by dopamine neurons explains selective toxicity. Proc Natl Acad Sci USA 82: 2173-2177, 1985.

25. Schapira AH, Cooper JM, Dexter D, Clark JB, Jenner P and Marsden CD: Mitochondrial complex I deficiency in Parkinson's disease. J Neurochem 54: 823-827, 1990.

26. Hattori N, Tanaka M, Ozawa $T$ and Mizuno $Y$ : Immunohistochemical studies on complexes I, II, III, and IV of mitochondria in Parkinson's disease. Ann Neurol 30: 563-571, 1991.

27. Mizuno Y, Ohta S, Tanaka M, Takamiya S, Suzuki K, Sato T, Oya H, Ozawa T and Kagawa Y: Deficiencies in complex I subunits of the respiratory chain in Parkinson's disease. Biochem Biophys Res Commun 163: 1450-1455, 1989.

28. Parker WD Jr, Parks JK and Swerdlow RH: Complex I deficiency in Parkinson's disease frontal cortex. Brain Res 1189: 215-218, 2008

29. Krige D, Carroll MT, Cooper JM, Marsden CD and Schapira AH; The Royal Kings and Queens Parkinson Disease Research Group: Platelet mitochondrial function in Parkinson's disease. Ann Neurol 32: 782-788, 1992.
30. Haas RH, Nasirian F, Nakano K, Ward D, Pay M, Hill R and Shults CW: Low platelet mitochondrial complex I and complex II/III activity in early untreated Parkinson's disease. Ann Neurol 37: 714-722, 1995.

31. Mytilineou C, Werner P, Molinari S, Di Rocco A, Cohen G and Yahr MD: Impaired oxidative decarboxylation of pyruvate in fibroblasts from patients with Parkinson's disease. J Neural Transm Park Dis Dement Sect 8: 223-228, 1994.

32. Blin O, Desnuelle C, Rascol O, Borg M, Peyro Saint Paul H, Azulay JP, Billé F, Figarella D, Coulom F, Pellissier JF, et al: Mitochondrial respiratory failure in skeletal muscle from patients with Parkinson's disease and multiple system atrophy. J Neurol Sci 125: 95-101, 1994.

33. Yoshino H, Nakagawa-Hattori Y, Kondo T and Mizuno Y: Mitochondrial complex I and II activities of lymphocytes and platelets in Parkinson's disease. J Neural Transm Park Dis Dement Sect 4: 27-34, 1992

34. Wen Y, Li W, Poteet EC, Xie L, Tan C, Yan LJ, Ju X, Liu R, Qian H, Marvin MA, et al: Alternative mitochondrial electron transfer as a novel strategy for neuroprotection. J Biol Chem 286: 16504-16515, 2011.

35. Kudin AP, Debska-Vielhaber G and Kunz WS: Characterization of superoxide production sites in isolated rat brain and skeletal muscle mitochondria. Biomed Pharmacother 59: 163-168, 2005.

36. Kudin AP, Bimpong-Buta NY, Vielhaber S, Elger CE and Kunz WS: Characterization of superoxide-producing sites in isolated brain mitochondria. J Biol Chem 279: 4127-4135, 2004.

37. Kussmaul L and Hirst J: The mechanism of superoxide production by NADH:ubiquinone oxidoreductase (complex I) from bovine heart mitochondria. Proc Natl Acad Sci USA 103: 7607-7612, 2006

38. Morán M, Moreno-Lastres D, Marín-Buera L, Arenas J, Martín MA and Ugalde C: Mitochondrial respiratory chain dysfunction: Implications in neurodegeneration. Free Radic Biol Med 53: 595-609, 2012

39. Dias V, Junn E and Mouradian MM: The role of oxidative stress in Parkinson's disease. J Parkinsons Dis 3: 461-491, 2013.

40. Morató L, Bertini E, Verrigni D, Ardissone A, Ruiz M, Ferrer I, Uziel G and Pujol A: Mitochondrial dysfunction in central nervous system white matter disorders. Glia 62: 1878-1894, 2014

41. Sian-Hülsmann J, Mandel S, Youdim MB and Riederer P: The relevance of iron in the pathogenesis of Parkinson's disease. J Neurochem 118: 939-957, 2011

42. Kosta P, Argyropoulou MI, Markoula S and Konitsiotis S: MRI evaluation of the basal ganglia size and iron content in patients with Parkinson's disease. J Neurol 253: 26-32, 2006.

43. Sziráki I, Mohanakumar KP, Rauhala P, Kim HG, Yeh KJ and Chiueh CC: Manganese: A transition metal protects nigrostriatal neurons from oxidative stress in the iron-induced animal model of parkinsonism. Neuroscience 85: 1101-1111, 1998.

44. Lan J and Jiang DH: Desferrioxamine and vitamin E protect against iron and MPTP-induced neurodegeneration in mice. J Neural Transm Vienna 104: 469-481, 1997.

45. Ruipérez V, Darios F and Davletov B: Alpha-synuclein, lipids and Parkinson's disease. Prog Lipid Res 49: 420-428, 2010.

46. Dexter DT, Carter CJ, Wells FR, Javoy-Agid F, Agid Y, Lees A, Jenner P and Marsden CD: Basal lipid peroxidation in substantia nigra is increased in Parkinson's disease. J Neurochem 52: 381-389, 1989.

47. Dexter DT, Holley AE, Flitter WD, Slater TF, Wells FR, Daniel SE, Lees AJ, Jenner P and Marsden CD: Increased levels of lipid hydroperoxides in the parkinsonian substantia nigra: An HPLC and ESR study. Mov Disord 9: 92-97, 1994.

48. Montine KS, Quinn JF, Zhang J, Fessel JP, Roberts LJ II, Morrow JD and Montine TJ: Isoprostanes and related products of lipid peroxidation in neurodegenerative diseases. Chem Phys Lipids 128: 117-124, 2004.

49. Liu W, Kato M, Akhand AA, Hayakawa A, Suzuki H Miyata T, Kurokawa K, Hotta Y, Ishikawa N and Nakashima I: 4-hydroxynonenal induces a cellular redox status-related activation of the caspase cascade for apoptotic cell death. J Cell Sci 113: 635-641, 2000.

50. Schmidt H, Grune T, Müller R, Siems WG and Wauer RR: Increased levels of lipid peroxidation products malondialdehyde and 4-hydroxynonenal after perinatal hypoxia. Pediatr Res 40: 15-20, 1996.

51. Starkov AA: The role of mitochondria in reactive oxygen species metabolism and signaling. Ann NY Acad Sci 1147: 37-52, 2008.

52. Murphy MP: How mitochondria produce reactive oxygen species. Biochem J 417: 1-13, 2009. 
53. Camara AK, Lesnefsky EJ and Stowe DF: Potential therapeutic benefits of strategies directed to mitochondria. Antioxid Redox Signal 13: 279-347, 2010.

54. Wallace DC: A mitochondrial paradigm of metabolic and degenerative diseases, aging, and cancer: A dawn for evolutionary medicine. Annu Rev Genet 39: 359-407, 2005.

55. Levy RJ and Deutschman CS: Deficient mitochondrial biogenesis in critical illness: Cause, effect, or epiphenomenon? Crit Care 11: $158,2007$.

56. Kraytsberg Y, Kudryavtseva E, McKee AC, Geula C, Kowall NW and Khrapko K: Mitochondrial DNA deletions are abundant and cause functional impairment in aged human substantia nigra neurons. Nat Genet 38: 518-520, 2006.

57. Bender A, Krishnan KJ, Morris CM, Taylor GA, Reeve AK, Perry RH, Jaros E, Hersheson JS, Betts J, Klopstock T, et al High levels of mitochondrial DNA deletions in substantia nigra neurons in aging and Parkinson disease. Nat Genet 38: 515-517, 2006.

58. Elstner M, Müller SK, Leidolt L, Laub C, Krieg L, Schlaudraff F, Liss B, Morris C, Turnbull DM, Masliah E, et al: Neuromelanin, neurotransmitter status and brainstem location determine the differential vulnerability of catecholaminergic neurons to mitochondrial DNA deletions. Mol Brain 4: 43, 2011.

59. Ekstrand MI, Terzioglu M, Galter D, Zhu S, Hofstetter C, Lindqvist $\mathrm{E}$, Thams S, Bergstrand A, Hansson FS, Trifunovic A, et al: Progressive parkinsonism in mice with respiratory-chain-deficient dopamine neurons. Proc Natl Acad Sci USA 104: 1325-1330, 2007.

60. Tanner CM, Kamel F, Ross GW, Hoppin JA, Goldman SM, Korell M, Marras C, Bhudhikanok GS, Kasten M, Chade AR, et al: Rotenone, paraquat, and Parkinson's disease. Environ Health Perspect 119: 866-872, 2011.

61. Takeuchi A, Kim B and Matsuoka S: The destiny of $\mathrm{Ca}(2+)$ released by mitochondria. J Physiol Sci 65: 11-24, 2015.

62. Jo H, Noma A and Matsuoka S: Calcium-mediated coupling between mitochondrial substrate dehydrogenation and cardiac workload in single guinea-pig ventricular myocytes. J Mol Cell Cardiol 40: 394-404, 2006

63. Satrústegui J, Pardo B and Del Arco A: Mitochondrial transporters as novel targets for intracellular calcium signaling. Physiol Rev 87: 29-67, 2007.

64. Kirichok Y, Krapivinsky G and Clapham DE: The mitochondrial calcium uniporter is a highly selective ion channel. Nature 427 360-364, 2004

65. Alderton WK, Cooper CE and Knowles RG: Nitric oxide synthases: Structure, function and inhibition. Biochem J 357: 593-615, 2001

66. Jekabsone A, Ivanoviene L, Brown GC and Borutaite V: Nitric oxide and calcium together inactivate mitochondrial complex I and induce cytochrome $c$ release. J Mol Cell Cardiol 35: 803-809, 2003.

67. Gandhi S, Wood-Kaczmar A, Yao Z, Plun-Favreau H, Deas E, Klupsch K, Downward J, Latchman DS, Tabrizi SJ, Wood NW, et al: PINK1-associated Parkinson's disease is caused by neuronal vulnerability to calcium-induced cell death. Mol Cell 33: 627-638, 2009.

68. Surmeier DJ, Guzman JN, Sanchez-Padilla J and Goldberg JA The origins of oxidant stress in Parkinson's disease and therapeutic strategies. Antioxid Redox Signal 14: 1289-1301, 2011.

69. Muravchick S and Levy RJ: Clinical implications of mitochondrial dysfunction. Anesthesiology 105: 819-837, 2006.

70. O'Rourke B: Pathophysiological and protective roles of mitochondrial ion channels. J Physiol 529: 23-36, 2000.

71. Di Lisa F and Bernardi P: A CaPful of mechanisms regulating the mitochondrial permeability transition. J Mol Cell Cardiol 46 775-780, 2009

72. Jones SP, Teshima Y, Akao M and Marbán E: Simvastatin attenuates oxidant-induced mitochondrial dysfunction in cardiac myocytes. Circ Res 93: 697-699, 2003.

73. Vila M and Przedborski S: Targeting programmed cell death in neurodegenerative diseases. Nat Rev Neurosci 4: 365-375, 2003.

74. Perier C, Tieu K, Guégan C, Caspersen C, Jackson-Lewis V, Carelli V, Martinuzzi A. Hirano M, Przedborski S and Vila M: Complex I deficiency primes Bax-dependent neuronal apoptosis through mitochondrial oxidative damage. Proc Natl Acad Sci USA 102: 19126-19131, 2005.

75. Halestrap AP and Brenner C: The adenine nucleotide translocase: A central component of the mitochondrial permeability transition pore and key player in cell death. Curr Med Chem 10: 1507-1525, 2003.
76. Adams JM and Cory S: The Bcl-2 protein family: Arbiters of cell survival. Science 281: 1322-1326, 1998.

77. Theruvath TP, Snoddy MC, Zhong Z and Lemasters JJ: Mitochondrial permeability transition in liver ischemia and reperfusion: Role of c-Jun N-terminal kinase 2. Transplantation 85: 1500-1504, 2008.

78. Theruvath TP, Zhong Z, Pediaditakis P, Ramshesh VK, Currin RT, Tikunov A, Holmuhamedov E and Lemasters JJ: Minocycline and N-methyl-4-isoleucine cyclosporin (NIM811) mitigate storage/reperfusion injury after rat liver transplantation through suppression of the mitochondrial permeability transition. Hepatology 47: 236-246, 2008.

79. Li P, Nijhawan D, Budihardjo I, Srinivasula SM, Ahmad M, Alnemri ES and Wang X: Cytochrome $c$ and dATP-dependent formation of Apaf-1/caspase-9 complex Initiates an apoptotic protease cascade. Cell 91: 479-489, 1997.

80. Liu X, Kim CN, Yang J, Jemmerson R and Wang X: Induction of apoptotic program in cell-free extracts: Requirement for dATP and cytochrome $c$. Cell 86: 147-157, 1996.

81. Kim GT, Chun YS, Park JW and Kim MS: Role of apoptosis-inducing factor in myocardial cell death by ischemia-reperfusion. Biochem Biophys Res Commun 309: 619-624, 2003.

82. Susin SA, Lorenzo HK, Zamzami N, Marzo I, Snow BE, Brothers GM, Mangion J, JacototE, Costantini P, Loeffler M, et al: Molecular characterization of mitochondrial apoptosis-inducing factor. Nature 397: 441-446, 1999.

83. Candé C, Cecconi F, Dessen $P$ and Kroemer G: Apoptosis-inducing factor (AIF): Key to the conserved caspase-independent pathways of cell death? J Cell Sci 115: 4727-4734, 2002.

84. Martin LJ: Biology of mitochondria in neurodegenerative diseases. Prog Mol Biol Transl Sci 107: 355-415, 2012.

85. Obame FN, Plin-Mercier C, Assaly R, Zini R, Dubois-Randé JL, Berdeaux A and Morin D: Cardioprotective effect of morphine and a blocker of glycogen synthase kinase 3 beta, SB216763 [3-(2,4-dichlorophenyl)-4(1-methyl-1H-indol-3-yl)-1H-pyrro le-2,5-dione], via inhibition of the mitochondrial permeability transition pore. J Pharmacol Exp Ther 326: 252-258, 2008.

86. Nishihara M, Miura T, Miki T, Tanno M, Yano T, Naitoh K, Ohori K, Hotta H, Terashima Y and Shimamoto K: Modulation of the mitochondrial permeability transition pore complex In GSK-3beta-mediated myocardial protection. J Mol Cell Cardiol 43: 564-570, 2007.

87. Jope RS and Johnson GV: The glamour and gloom of glycogen synthase kinase-3. Trends Biochem Sci 29: 95-102, 2004.

88. Kockeritz L, Doble B, Patel S and Woodgett JR: Glycogen synthase kinase-3 - an overview of an over-achieving protein kinase. Curr Drug Targets 7: 1377-1388, 2006.

89. Tan J, Zhuang L, Leong HS, Iyer NG, Liu ET and Yu Q: Pharmacologic modulation of glycogen synthase kinase-3beta promotes $\mathrm{p} 53$-dependent apoptosis through a direct Bax-mediated mitochondrial pathway in colorectal cancer cells. Cancer Res 65: 9012-9020, 2005.

90. Watcharasit P, Bijur GN, Song L, Zhu J, Chen X and Jope RS: Glycogen synthase kinase-3beta (GSK3beta) binds to and promotes the actions of p53. J Biol Chem 278: 48872-48879, 2003.

91. Linseman DA, Butts BD, Precht TA, Phelps RA, Le SS, Laessig TA, Bouchard RJ, Florez-McClure ML and Heidenreich KA: Glycogen synthase kinase-3beta phosphorylates Bax and promotes its mitochondrial localization during neuronal apoptosis. J Neurosci 24: 9993-10002, 2004.

92. King TD, Clodfelder-Miller B, Barksdale KA and Bijur GN: Unregulated mitochondrial GSK3beta activity results in NADH: Ubiquinone oxidoreductase deficiency. Neurotox Res 14: 367-382, 2008.

93. Wang W, Yang Y, Ying C, Li W, Ruan H, Zhu X, You Y, Han Y, Chen R, Wang Y, et al: Inhibition of glycogen synthase kinase-3beta protects dopaminergic neurons from MPTP toxicity. Neuropharmacology 52: 1678-1684, 2007.

94. King TD, Bijur GN and Jope RS: Caspase-3 activation induced by inhibition of mitochondrial complex I is facilitated by glycogen synthase kinase-3beta and attenuated by lithium. Brain Res 919: 106-114, 2001.

95. Petit-Paitel A, Brau F, Cazareth J and Chabry J: Involvement of cytosolic and mitochondrial GSK-3beta in mitochondrial dysfunction and neuronal cell death of MPTP/MPP-treated neurons. PLoS One 4: e5491, 2009. 
96. Youdim MB and Arraf Z: Prevention of MPTP (N-methyl-4-phenyl-1,2,3,6-tetrahydropyridine) dopaminergic neurotoxicity in mice by chronic lithium: Involvements of Bcl-2 and Bax. Neuropharmacology 46: 1130-1140, 2004.

97.Li DW, Liu ZQ, Chen W, Yao M and Li GR: Association of glycogen synthase kinase- $3 \beta$ with Parkinson's disease (Review). Mol Med Rep 9: 2043-2050, 2014.

98. Spencer JP, Vafeiadou K, Williams RJ and Vauzour D: Neuroinflammation: Modulation by flavonoids and mechanisms of action. Mol Aspects Med 33: 83-97, 2012.

99.Pimplikar SW: Neuroinflammation in Alzheimer's disease: From pathogenesis to a therapeutic target. J Clin Immunol 34 (Suppl 1): S64-S69, 2014.

100. Möller T: Neuroinflammation in Huntington's disease. J Neural Transm Vienna 117: 1001-1008, 2010

101. Frohman EM, Racke MK and Raine CS: Multiple sclerosis - the plaque and its pathogenesis. N Engl J Med 354: 942-955, 2006.

102. Hirsch EC, Vyas S and Hunot S: Neuroinflammation in Parkinson's disease. Parkinsonism Relat Disord 18 (Suppl 1): S210-S212, 2012

103.Zhang F and Jiang L: Neuroinflammation in Alzheimer's disease. Neuropsychiatr Dis Treat 11: 243-256, 2015.

104. Block ML, Zecca L and Hong JS: Microglia-mediated neurotoxicity: Uncovering the molecular mechanisms. Nat Rev Neurosci 8: 57-69, 2007.

105. Ceulemans AG, Zgavc T, Kooijman R, Hachimi-Idrissi S Sarre S and Michotte Y: The dual role of the neuroinflammatory response after ischemic stroke: Modulatory effects of hypothermia. J Neuroinflammation 7: 74, 2010.

106. Chéret C, Gervais A, Lelli A, Colin C, Amar L, Ravassard P, Mallet J, Cumano A, Krause KH and Mallat M: Neurotoxic activation of microglia is promoted by a nox 1-dependent NADPH oxidase. J Neurosci 28: 12039-12051, 2008.

107. McGeer PL and McGeer EG: Glial reactions in Parkinson's disease. Mov Disord 23: 474-483, 2008.

108. Frankola KA, Greig NH, Luo W and Tweedie D: Targeting TNF- $\alpha$ to elucidate and ameliorate neuroinflammation in neurodegenerative diseases. CNS Neurol Disord Drug Targets 10 391-403, 2011.

109. Qian L, Flood PM and Hong JS: Neuroinflammation is a key player in Parkinson's disease and a prime target for therapy. J Neural Transm Vienna 117: 971-979, 2010

110. Hunot S, Dugas N, Faucheux B, Hartmann A, Tardieu M, Debré P, Agid Y, Dugas B and Hirsch EC: FcepsilonRII/CD23 is expressed in Parkinson's disease and induces, in vitro, production of nitric oxide and tumor necrosis factor-alpha in glial cells. J Neurosci 19: 3440-3447, 1999.

111. Mogi M, Harada M, Narabayashi H, Inagaki H, Minami M and Nagatsu T: Interleukin (IL)-1 beta, IL-2, IL-4, IL-6 and transforming growth factor-alpha levels are elevated in ventricular cerebrospinal fluid in juvenile parkinsonism and Parkinson's disease. Neurosci Lett 211: 13-16, 1996.

112. Hirsch EC, Breidert T, Rousselet E, Hunot S, Hartmann A and Michel PP: The role of glial reaction and inflammation in Parkinson's disease. Ann NY Acad Sci 991: 214-228, 2003.

113. Herrera AJ, Castaño A, Venero JL, Cano J and Machado A: The single intranigral injection of LPS as a new model for studying the selective effects of inflammatory reactions on dopaminergic system. Neurobiol Dis 7: 429-447, 2000.

114. Iravani MM, Leung CC, Sadeghian M, Haddon CO, Rose S and Jenner P: The acute and the long-term effects of nigral lipopolysaccharide administration on dopaminergic dysfunction and glial cell activation. Eur J Neurosci 22: 317-330, 2005.

115. Iravani MM, Sadeghian M, Leung CC, Jenner P and Rose S: Lipopolysaccharide-induced nigral inflammation leads to increased IL-1 $\beta$ tissue content and expression of astrocytic glial cell line-derived neurotrophic factor. Neurosci Lett 510 $138-142,2012$

116. Kohutnicka M, Lewandowska E, Kurkowska-Jastrzebska I, Członkowski A and Członkowska A: Microglial and astrocytic involvement in a murine model of Parkinson's disease induced by 1-methyl-4-phenyl-1,2,3,6-tetrahydropyridine (MPTP) Immunopharmacology 39: 167-180, 1998.

117. Członkowska A, Kohutnicka M, Kurkowska-Jastrzebska I and Członkowski A: Microglial reaction in MPTP (1-methyl-4-phenyl-1,2,3,6-tetrahydropyridine) induced Parkinson's disease mice model. Neurodegeneration 5: 137-143, 1996.

118. Sriram K, Miller DB and O'Callaghan JP: Minocycline attenuates microglial activation but fails to mitigate striatal dopaminergic neurotoxicity: Role of tumor necrosis factor-alpha. J Neurochem 96: 706-718, 2006.
119. Mogi M, Harada M, Riederer P, Narabayashi H, Fujita K and Nagatsu T: Tumor necrosis factor-alpha (TNF-alpha) increases both in the brain and in the cerebrospinal fluid from parkinsonian patients. Neurosci Lett 165: 208-210, 1994

120. Mir M, Tolosa L, Asensio VJ, Lladó J and Olmos G Complementary roles of tumor necrosis factor alpha and interferon gamma in inducible microglial nitric oxide generation. J Neuroimmunol 204: 101-109, 2008

121. Lawson LJ, Perry VH, Dri P and Gordon S: Heterogeneity in the distribution and morphology of microglia in the normal adult mouse brain. Neuroscience 39: 151-170, 1990.

122. Kim WG, Mohney RP, Wilson B, Jeohn GH, Liu B and Hong JS: Regional difference in susceptibility to lipopolysaccharide-induced neurotoxicity in the rat brain: Role of microglia. J Neurosci 20: 6309-6316, 2000

123. Liberatore GT, Jackson-Lewis V, Vukosavic S, Mandir AS, Vila M, McAuliffe WG, Dawson VL, Dawson TM and Przedborski S: Inducible nitric oxide synthase stimulates dopaminergic neurodegeneration in the MPTP model of Parkinson disease. Nat Med 5: 1403-1409, 1999.

124.Zhang F, Qian L, Flood PM, Shi JS, Hong JS and Gao HM Inhibition of IkappaB kinase-beta protects dopamine neurons against lipopolysaccharide-induced neurotoxicity. J Pharmacol Exp Ther 333: 822-833, 2010.

125.Lofrumento DD, Nicolardi G, Cianciulli A, De Nuccio F, La Pesa V, Carofiglio V, Dragone T, Calvello R and Panaro MA: Neuroprotective effects of resveratrol in an MPTP mouse model of Parkinson's-like disease: Possible role of SOCS-1 in reducing pro-inflammatory responses. Innate Immun 20 : 249-260, 2014.

126. Gao HM, Zhou H, Zhang F, Wilson BC, Kam W and Hong JS HMGB1 acts on microglia Mac1 to mediate chronic neuroinflammation that drives progressive neurodegeneration. J Neurosci 31: 1081-1092, 2011.

127. Gao HM and Hong JS: Why neurodegenerative diseases are progressive: Uncontrolled inflammation drives disease progression. Trends Immunol 29: 357-365, 2008.

128. Evans MD, Dizdaroglu M and Cooke MS: Oxidative DNA damage and disease: Induction, repair and significance. Mutat Res 567: 1-61, 2004.

129. Hegde ML, Gupta VB, Anitha M, Harikrishna T, Shankar SK, Muthane U, Subba Rao K and Jagannatha Rao KS: Studies on genomic DNA topology and stability in brain regions of Parkinson's disease. Arch Biochem Biophys 449: 143-156, 2006.

130. Maynard S, de Souza-Pinto NC, Scheibye-Knudsen M and Bohr VA: Mitochondrial base excision repair assays. Methods 51: 416-425, 2010.

131. Sanders LH, McCoy J, Hu X, Mastroberardino PG, Dickinson BC, Chang CJ, Chu CT, Van Houten B and Greenamyre JT: Mitochondrial DNA damage: Molecular marker of vulnerable nigral neurons in Parkinson's disease. Neurobiol Dis 70: 214-223, 2014.

132. Wilson DM III and Barsky D: The major human abasic endonuclease: Formation, consequences and repair of abasic lesions in DNA. Mutat Res 485: 283-307, 2001.

133. Larsen E, Reite K, Nesse G, Gran C, Seeberg E and Klungland A: Repair and mutagenesis at oxidized DNA lesions in the developing brain of wild-type and $\mathrm{Ogg}^{1 /-}$ mice. Oncogene 25 : 2425-2432, 2006

134. Gencer M, Dasdemir S, Cakmakoglu B, Cetinkaya Y, Varlibas F, Tireli H, Kucukali CI, Ozkok E and Aydin M: DNA repair genes in Parkinson's disease. Genet Test Mol Biomarkers 16: 504-507, 2012.

135. Mailand N, Gibbs-Seymour I and Bekker-Jensen S: Regulation of PCNA-protein interactions for genome stability. Nat Rev Mol Cell Biol 14: 269-282, 2013.

136. Moldovan GL, Pfander B and Jentsch S: PCNA, the maestro of the replication fork. Cell 129: 665-679, 2007.

137. Burkovics P, Hajdú I, Szukacsov V, Unk I and Haracska L: Role of PCNA-dependent stimulation of 3'-phosphodiesterase and 3'-5' exonuclease activities of human Ape 2 in repair of oxidative DNA damage. Nucleic Acids Res 37: 4247-4255, 2009.

138. Amoroso A, Concia L, Maggio C, Raynaud C, Bergounioux C, Crespan E, Cella R and Maga G: Oxidative DNA damage bypass in Arabidopsis thaliana requires DNA polymerase $\lambda$ and proliferating cell nuclear antigen 2. Plant Cell 23: 806-822, 2011.

139. Li DW, Li GR, Zhang BL, Feng JJ and Zhao H: Damage to dopaminergic neurons is mediated by proliferating cell nuclear antigen through the $\mathrm{p} 53$ pathway under conditions of oxidative stress in a cell model of Parkinson's disease. Int J Mol Med 37: 429-435, 2016. 